\title{
Correction to: Life cycle and phenology of an Antarctic invader: the flightless chironomid midge, Eretmoptera murphyi
}

\author{
Jesamine C. Bartlett ${ }^{1} \cdot$ Peter Convey $^{2} \cdot$ Scott A. L. Hayward $^{1}$
}

Published online: 23 October 2018

๑) Springer-Verlag GmbH Germany, part of Springer Nature 2018

\section{Correction to: Polar Biology \\ https://doi.org/10.1007/s00300-018-2403-5}

This correction serves to provide the correct rendering of Fig. 1a, with its respective insets corrected to show both the South Orkney Islands and Signy Island (not shown in the original article but showing in the corrected figure below).

Scott A. L. Hayward

s.a.hayward@bham.ac.uk

1 School of Biosciences, University of Birmingham, Edgbaston B15 2TT, UK

2 British Antarctic Survey, NERC, High Cross, Madingley Road, Cambridge CB3 0ET, UK 


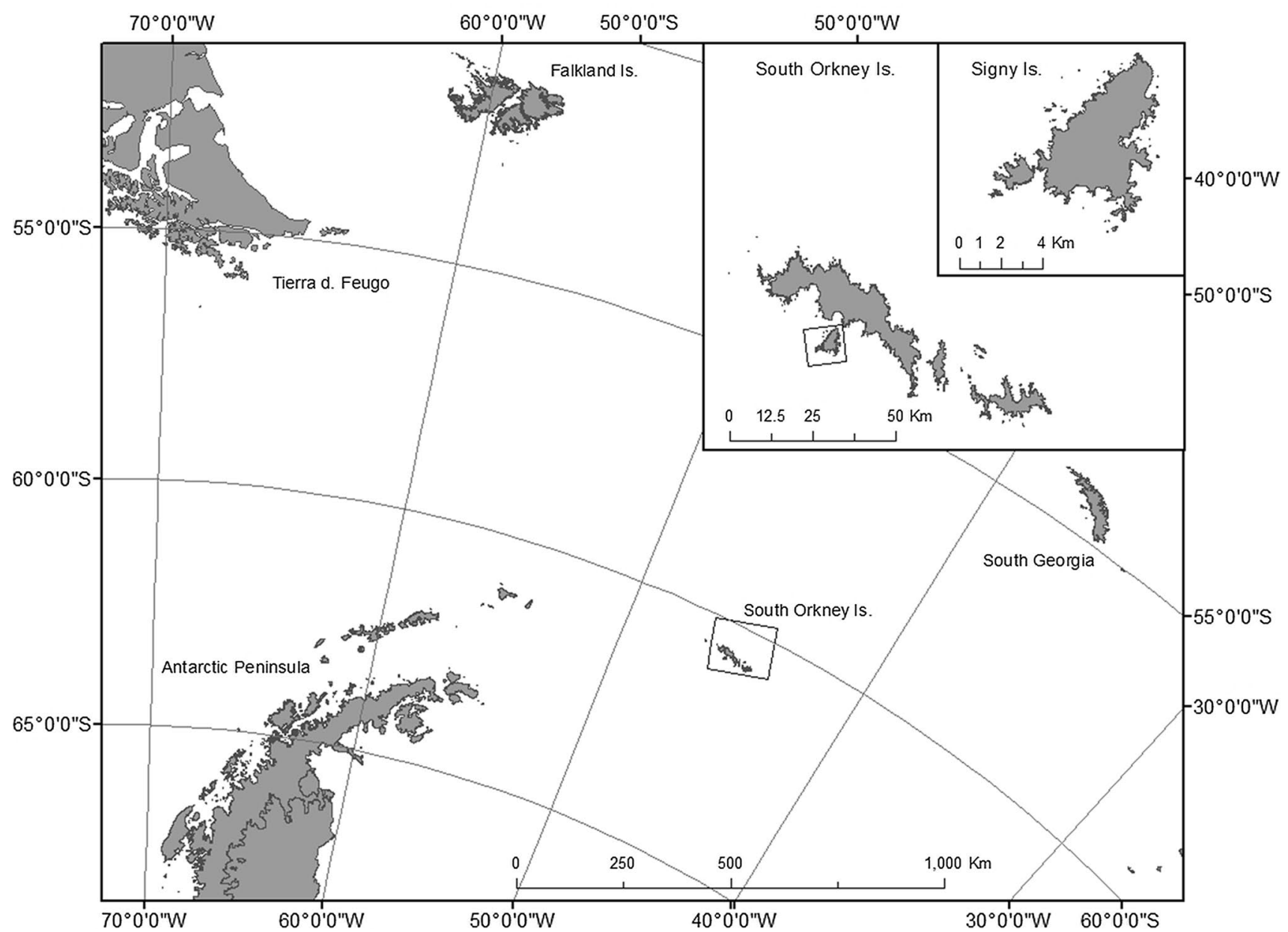

Fig. 1 Maps showing the Location of the South Orkney Islands and Signy Island in the Southern Ocean. Inset-Map of Signy Island, with Research Station (and thus current area of E. murphyi distribu- tion) highlighted. Created using ArcMap®10.4.1 software by Esri. Copyright (C) Esri 